\title{
Rituximab in Combination with Gemcitabine Plus \\ Cisplatin in Patients with Recurrent and Metastatic Head and Neck Squamous Cell Carcinoma: A Phase I Trial
}

\section{Ching-Yun Hsieh}

China Medical University Hospital, China Medical University

Ming-Yu Lien

China Medical University Hospital, China Medical University

Chen-Yuan Lin

China Medical University Hospital, China Medical University

Wen-Jyi Lo

China Medical University Hospital, China Medical University

Chung-Hung Hua

China Medical University Hospital, China Medical University

Wei-Chao Chang

China Medical University Hospital, China Medical University

Chang-Fang Chiu

China Medical University Hospital, China Medical University

Ching-Chan Lin ( $\sim$ d13256@mail.cmuh.org.tw)

China Medical University Hospital, China Medical University

\section{Research Article}

Keywords: head and neck squamous-cell carcinoma, rituximab, chemotherapy, anti-CD20 antibody

Posted Date: November 1st, 2021

DOI: https://doi.org/10.21203/rs.3.rs-941886/v1

License: (c) (i) This work is licensed under a Creative Commons Attribution 4.0 International License. Read Full License

Version of Record: A version of this preprint was published at BMC Cancer on February 15th, 2022. See the published version at https://doi.org/10.1186/s12885-022-09258-0. 


\section{Abstract}

\section{Background}

The treatment of recurrent or metastatic head and neck squamous-cell carcinoma (R/M HNSCC) remains challenging. Preclinical studies revealed that $B$ cell depletion could modulate the microenvironment and overcome chemoresistance. We conducted a phase I study to evaluate the feasibility and safety of B cell depletion using the anti-CD20 antibody rituximab to treat HNSCC.

\section{Methods}

Ten patients were enrolled into two protocols. The first four patients treated using protocol 1 received rituximab 1000 $\mathrm{mg}$ on days -14 and -7 , followed by gemcitabine/cisplatin every 3 weeks, and rituximab was administered every 6 months thereafter. Because of disease hyperprogression, protocol 1 was amended to protocol 2, which consisted of the concomitant administration of rituximab $375 \mathrm{mg} / \mathrm{m}^{2}$ and gemcitabine/cisplatin every 3 weeks. Another six patients were enrolled and treated using protocol 2.

\section{Results}

Three patients treated using protocol 1 exhibited rapid disease progression, and the remaining patient could not undergo evaluation after rituximab treatment. Conversely, no unpredicted harm was observed in the six patients treated using protocol 2 . Among these patients, one achieved complete response, and two had partial responses. The disease-free durations in these patients were 7.0,6.2, and 7.1 months, respectively. Immune cell analysis revealed a higher ratio of cytotoxic $\mathrm{T}$ cells to regulatory $\mathrm{T}$ cells in responders than in non-responders.

\section{Conclusions}

B cell depletion using rituximab alone in patients with HNSCC can cause hyperprogressive disease. Contrarily, the coadministration of rituximab and cisplatin/gemcitabine was feasible and safe.

\section{Trial registration:}

ClinicalTrials.gov Identifier: NCT04361409, 24/April/2020, retrospectively registered, https://clinicaltrials.gov/ct2/show/study/NCT04361409

\section{Background}

Recurrent or metastatic squamous-cell carcinoma of the head and neck (R/M HNSCC) has a dismal prognosis [1]. Systemic therapies such as chemotherapy or targeted therapy against EGFR have been the mainstay of palliation [2], but long-term disease control is difficult. The development of programmed death 1 (PD-1) immune checkpoint inhibitors changed the treatment of HNSCC. Pembrolizumab produced a durable response rate and better overall survival than cetuximab plus platinum chemotherapy [3]. However, only one-third of patients respond to this treatment, and the median progression-free survival is approximately 5 months. Therefore, novel therapies are urgently required for patients with R/M HNSCC.

The importance of $B$ cells in the tumor microenvironment (TME) has been increasingly investigated [4]. An animal study demonstrated that CD20+B cells are responsible for chemoresistance to platinum agents and taxanes in HNSCC [5]. B cell depletion reduced chemotherapy resistance of squamous-cell carcinoma in mouse models [5]. 
Clinically, the anti-CD20 antibody rituximab has been effectively used to directly target CD20+ hematologic malignancies [6, 7]. A case series identified rituximab as a therapeutic option for advanced malignant melanoma [8], and a study in colon cancer demonstrated that rituximab reduced $\mathrm{B}$ cell counts and exerted a considerable clinical effect [9].

Gemcitabine produces a modest response rate (0-13\%) as a single agent in patients with R/M HNSCC [10]. Synergistic activity between gemcitabine and cisplatin was observed in preclinical and clinical data [11]. Gemcitabine more potently inhibits B cell proliferation than T cell proliferation [12]. Therefore, gemcitabine may be a practical treatment option in conjunction with a variety of immunotherapies for B cell depletion.

As B cell depletion was hypothesized to improve chemotherapeutic efficacy in HNSCC in preclinical studies, we conducted a pilot study to investigate the feasibility of rituximab combined with gemcitabine/cisplatin in R/M HNSCC.

\section{Methods}

\section{Patients and study design}

This open-label phase I pilot study (ClinicalTrials.gov Identifier: NCT04361409, 24/April/2020) examined the feasibility of the combination of rituximab and gemcitabine plus cisplatin in patients with R/M HNSCC. Eligible patients were more than 20 years old with histologically confirmed HNSCC. All patients had surgically unresectable lesions that progressed on standard treatment and no available effective treatment option at the time of study enrollment. The other main eligibility criteria included an Eastern Cooperative Oncology Group performance status of 0-2 and adequate organ function. Key exclusion criteria were brain metastases, spinal cord compression, and only bone metastasis.

The study enrolled 10 patients with R/M HNSCC in China Medical University Hospital, Taiwan. The study was conducted in accordance with the World Medical Association Declaration of Helsinki (version 2002) and approved by the China Medical University Hospital Review Board. Patients provided IRB-approved, protocol-specific written informed consent prior to receiving study-specific treatment.

Initially, the protocol (protocol 1) was designed to administer rituximab to deplete B cells before the administration of chemotherapy. Intravenous rituximab $1000 \mathrm{mg}$ intravenously was administered on days -14 and -7 and every 6 months thereafter. Chemotherapy featuring cisplatin $\left(70 \mathrm{mg} / \mathrm{m}^{2}\right.$ intravenously) on day 1 and gemcitabine (1000 $\mathrm{mg} / \mathrm{m}^{2}$ intravenously) on days 1 and 8 was administered every 21 days. After four patients were enrolled into protocol 1, the protocol was amended to administer rituximab (375 mg/m² intravenously) on Day 1 , followed by cisplatin and gemcitabine using the previously mentioned doses and schedule (protocol 2). Six patients were treated using protocol 2. The protocol schemes are presented in Table 1.

Table 1. Protocol schemes 


\begin{tabular}{|lll|}
\hline & Protocol $\mathbf{1}(\mathbf{n}=\mathbf{4})$ & Protocol $\mathbf{2}(\mathbf{n}=\mathbf{6})$ \\
\hline Rituximab & $\begin{array}{l}1000 \mathrm{mg} \text { on days }-14 \text { and }-7 \text {, followed by treatment } \\
\text { every } 6 \text { months }\end{array}$ & $375 \mathrm{mg} / \mathrm{m}^{2}$ on day 1 every 3 weeks \\
\hline Cisplatin & $70 \mathrm{mg} / \mathrm{m}^{2}$ on day 1 every 3 weeks & $70 \mathrm{mg} / \mathrm{m}^{2}$ on day 1 every 3 weeks \\
\hline Gemcitabine & $1000 \mathrm{mg} / \mathrm{m}^{2}$ on days 1 and 8 every 3 weeks & $\begin{array}{l}1000 \mathrm{mg} / \mathrm{m}^{2} \text { on days } 1 \text { and } 8 \text { every } \\
3 \text { weeks }\end{array}$ \\
\hline
\end{tabular}

\section{Endpoints and disease response}

The primary objective was to determine the feasibility of the combination of rituximab and gemcitabine/cisplatin in patients with R/M HNSCC, whereas the secondary objectives included the response rate, progression-free survival (PFS), and toxicity.

The major objective measurement for feasibility was to identify unpredicted harm during the course of combination treatment. The two feasibility objectives of our pilot study were to assess (1) unpredicted harm during the course of rituximab administration and (2) compliance with post-rituximab examination. The feasibility objectives for our study were considered successful if the following criteria were met: (1) $80 \%$ of patients who received rituximab experienced no unpredicted harm during the course of rituximab administration and (2) $80 \%$ of patients could undergo examination 1 week after rituximab administration. Unpredicted harm was defined as death within 1 month after rituximab administration, severe infection or grade 3 tumor bleeding within 1 month after rituximab administration, or patient refusal to complete the second cycle of rituximab therapy.

PFS was defined as the time from study registration to the first day of disease progression at any site or of death by any cause. The response assessment was performed using computed tomography (CT) at the end of treatment according to RECIST 1.1. CT was performed every 8-12 weeks until disease progression. Furthermore, toxicities were assessed at each weekly visit during treatment and at the end of treatment and recorded by the investigators using NCl-CTCAE version 4.03 .

\section{Evaluation of tumor growth kinetics ratios (TGKRs)}

To evaluate TGKRs, patients underwent pre-baseline, baseline, and post-treatment CT. The minimal interval between two CT scans was 14 days, and patients were required to start rituximab within 1 week after the baseline scan. Tumor growth kinetics before $\left(\mathrm{TGK}_{\text {pre }}\right)$ and after $\left(\mathrm{TGK}_{\text {post }}\right)$ rituximab were evaluated. $\mathrm{TGK}_{\text {pre }}$ was defined as the difference of the sum of the largest diameters of the target lesions per unit of time between pre-baseline and baseline imaging [13]. TGK post $_{\text {was }}$ wefined in the same manner between on-treatment and post-treatment imaging. TGKR was calculated using RECIST 1.1 as the ratio of TGK post to $T G_{\text {pre. }}$. Hyperprogressive disease (HPD) was defined as TGKR $\geq 2$. Tumor growth acceleration was indicated by $2>T G K R>1$, whereas $0<T G K R<1$ indicated tumor deceleration. TGKR $<0$ indicated tumor shrinkage [13].

\section{Immune cell evaluation}

Peripheral blood was obtained from patients prior to treatment and on day 7 after the administration of rituximab. At least $5 \times 10^{5}$ events per sample were acquired on a six-color flow cytometer (BD FACSCanto II). Immunophenotypes 
were analyzed using CD20-FITC, CD16-PE, CD14-PerCP, CD19-APC, CD45-APC-H7, CD3-PE-C7, CD4-APC, CD127-PerCP, CD25-FITC, and CD8-FITC. Data analysis was performed using Infinicyt software (Cytognos, Salamanca, Spain).

\section{Statistical analysis}

Statistical analysis was performed using SPSS 26 (SPSS Inc.). Graphs were created using GraphPad Prism version 7 (GraphPad software Inc.). The Mann-Whitney U test was used to compare continuous variables in all comparisons. Statistical significance was defined as $p$-value $<0.05$.

\section{Results}

\section{General characteristics}

Ten patients, all of whom were men, were enrolled in the study between August 2013 and September 2016. The patients' characteristics are presented in Table 2. The median patient age was 47.5 (range, 33-61). The site of disease was the hypopharynx-oropharynx in two patients, the buccal space in two patients, and the tongue in two patients. Four patient developed distant metastases, and six had localized progression. All patients were cisplatinrefractory. Five patients (Patient Nos. 1-5) experienced progression despite receiving a cetuximab-containing regimen. Nine patients were refractory to concurrent chemoradiotherapy (Patient Nos. 1-6 and 8-10). No patients had received immune checkpoint inhibitors at the time of study enrollment.

Table 2. Patients' demographic data

\begin{tabular}{|llllllllll|}
\hline $\begin{array}{l}\text { Patient } \\
\text { no. }\end{array}$ & $\begin{array}{l}\text { Age } \\
\text { (years) }\end{array}$ & Site & $\begin{array}{l}\text { Previous } \\
\text { lines of } \\
\text { treatment }\end{array}$ & $\begin{array}{l}\text { Recurrence } \\
\text { type }\end{array}$ & $\begin{array}{l}\text { Cisplatin } \\
\text { failure }\end{array}$ & $\begin{array}{l}\text { Treatment } \\
\text { schedule }\end{array}$ & $\begin{array}{l}\text { Best } \\
\text { response }\end{array}$ & $\begin{array}{l}\text { PFS } \\
\text { (months) }\end{array}$ \\
\hline $\mathbf{1}$ & 47 & Buccal space & 3 & local & Yes & R then CT & SD & 6.3 \\
\hline $\mathbf{2}$ & 38 & Buccal space & 3 & local & Yes & R then CT & PD & 1.9 \\
\hline $\mathbf{3}$ & 49 & Hypopharynx & 3 & local & Yes & R then CT & PD & 1.1 \\
\hline $\mathbf{4}$ & 49 & Hypopharynx & 3 & Local & Yes & R then CT & PD & 1.9 \\
\hline $\mathbf{5}$ & 39 & Tongue & 2 & Local & Yes & R plus CT & PR & 7.0 \\
\hline $\mathbf{6}$ & $\mathbf{4 8}$ & Hypopharynx & 2 & Distant & Yes & R plus CT & CR & 6.2 \\
\hline $\mathbf{7}$ & $\mathbf{6 1}$ & Hypopharynx & $\mathbf{1}$ & Distant & Yes & R plus CT & PD & 1.6 \\
\hline $\mathbf{8}$ & 33 & Tongue & 3 & Local & Yes & R plus CT & PD & 0.7 \\
\hline $\mathbf{9}$ & 48 & Oropharynx & 2 & Distant & Yes & R plus CT & PR & 7.1 \\
\hline $\mathbf{1 0}$ & 45 & Oropharynx & 2 & Local & Yes & R plus CT & SD & 3.0 \\
\hline
\end{tabular}

PFS, progression-free survival; R, rituximab; CT chemotherapy; SD, stable disease; PD, progressive disease; PR, partial response; $\mathrm{CR}$, complete response 
The first four patients (Patient Nos. 1-4) were treated using protocol 1. Three of these patients completed all evaluations after treatment, and the remaining patient (Patient No. 4) could not undergo CT because of upper airway compression secondary to disease progression. Patient No. 5 initially received rituximab 1000 mg on day -14 . However, his tongue pain worsened, and an episode of tumor bleeding occurred 3 days later. After suspecting disease progression, salvage chemotherapy with gemcitabine and cisplatin was administered. The tumor bleeding subsided, and his tongue pain improved obviously. Following discussions with the local IRB, we amended the protocol to include the co-administration of rituximab with gemcitabine/cisplatin every 3 weeks (protocol 2). Finally, six patients, including Patient No. 5, were treated using protocol 2. No unexpected adverse effects were observed in patients treated using protocol 2 , and all patients could be evaluated 1 week after rituximab administration.

The other adverse events during treatment are presented in Table 3. Most patients had grade 1-2 side effects, but two patients each had grade 3-4 nausea and grade 3-4 oral mucositis. The grade 3-4 hematologic side effects included grade 3-4 neutropenia in three patients, grade 3-4 anemia in two patients, and febrile neutropenia in two patients.

Table 3. Adverse events graded using NCI-CTCAE version 4.03

\begin{tabular}{|c|c|c|}
\hline NICIC CTG grade & Grade 1-2 & Grade 3-4 \\
\hline \multicolumn{3}{|c|}{ During induction chemotherapy $(n=10)$} \\
\hline Anemia & 5 & 1 \\
\hline Neutropenia & 5 & 3 \\
\hline Thrombocytopenia & 1 & 0 \\
\hline Alopecia & 3 & \\
\hline Mucositis/stomatitis & 3 & 1 \\
\hline Febrile neutropenia & 2 & \\
\hline Nausea & 5 & 2 \\
\hline Vomiting & 1 & 0 \\
\hline Fatigue & 7 & 1 \\
\hline Peripheral neuropathy & 2 & 0 \\
\hline
\end{tabular}

\section{Response evaluation}

In protocol 1, three patients experienced disease progression, and one patient had a best response of stable disease (Patient No. 1). In protocol 2, three patients responded to treatment, including one complete response (Patient No. 6) and two partial responses (Patient Nos. 5 and 9). Two patients experienced disease progression, and the remaining patient had stable disease. Among the five patients experiencing clinical benefits (including complete responses, partial responses, and stable disease), the median duration of response was 6 months (range, 3-7.1). The waterflow plot of the patients' best responses is presented in Fig. 1. The representative CT findings of one responder (Patient No. 5) before and after treatment are presented in Fig. 2. 
Because we observed rapid disease progression in Patient No. 5 shortly after the administration of rituximab, we questioned whether B cell depletion using rituximab monotherapy could cause HPD. We used TGKR to evaluate tumor growth rates in patients with disease progression [14]. TGKR could be evaluated in three patients treated using protocol 1 (Patient Nos. 2-4). All three patients experienced HPD, as presented in Fig. 3. Regarding patients treated using protocol 2 who experienced disease progression (Patient Nos. 7-8), Patient No. 8 could not undergo CT after disease progression because superior vena cava syndrome prevented him from adopting the supine position during the examination. Therefore, we only evaluated TGFR in Patient No. 7, and no evidence of HPD was detected, as illustrated in Fig. 3.

\section{Immune cell evaluation}

We investigated the changes of immune cell counts in peripheral blood. We found B cells were significantly depleted in all patients after rituximab administration $(p=0.013)$. We examined the counts of B cells (CD19+CD20+), cytotoxic T cells (CD3+CD8+), helper T cells (CD3+CD4+), regulatory T cells (CD3+CD4+CD25+CD127-), classical monocytes (CD14+CD16-), non-classical monocytes (CD14-CD16+), and intermediate monocytes (CD14+CD16+) to analyze whether the immune cell counts in peripheral blood were correlated with treatment responses. The results demonstrated that responders had a significantly higher ratio of cytotoxic $T$ cells/regulatory $T$ cells in peripheral blood before rituximab treatment than non-responders $(p=0.017)$ (Fig. 4). No differences were detected in the counts of other immune cells between responders and non-responders.

\section{Discussion}

This pilot study investigated the feasibility of rituximab combined with chemotherapy in patients with R/M HNSCC. Our study featured two treatment protocols. In protocol 1, rituximab monotherapy was used in the first 2 weeks to deplete B cells, followed by chemotherapy. One patient had an unpredicted adverse event. In addition, we analyzed the outcomes of the first four patients and found that three patients had rapid disease progression after treatment. We altered the treatment regimen to co-administer rituximab and chemotherapy on the same day. Six patients were enrolled in protocol 2, and no patients reported unpredicted adverse events. Therefore, it appeared feasible and safe to simultaneously co-administer rituximab and cytotoxic agents in patients with HNSCC, but rituximab monotherapy should not be provided to these patients because of its high risks of HPD.

The function of B cells in the TME remains controversial. A meta-analysis of expression signatures from 18,000 human tumors demonstrated that the presence of plasma cells portended good survival outcomes [15]. Plasma cells release anti-tumor antibodies to induce antibody-dependent cell cytotoxicity and phagocytosis in tumor cells [16, 17]. Recent studies demonstrated that the presence of B cells within tertiary lymphoid structures was associated with the response to immune checkpoint blockade in melanoma, renal cell carcinoma, and soft tissue sarcoma [18-20]. Conversely, B cells also can promote tumorigenesis and attenuate anti-tumor immunity [21, 22]. The presence of memory B cells is a poor prognostic factor for lung squamous-cell carcinoma, gastric cancer, and colon cancer [15]. In an experimental study, B cells produced lymphotoxin and circulating immune complexes to promote carcinogenesis $[23,24]$. In addition, regulatory B cells secrete various inhibitory cytokines and molecules such as IL10 and IL-35 to suppress effector T cells and promote regular T cell formation $[25,26]$. B cell depletion using antiCD20 agents regulated the phenotype of tumor-associated macrophages and inhibited tumorigenesis and cancer growth in a mouse HNSCC model [5]. In addition, administration of an anti-CD 20 agent before chemotherapy will improve the efficacy of chemotherapy in vivo [5]. Therefore, preclinical studies demonstrated the complex and diverse roles of B cells in tumor growth. Our clinical observation that rituximab alone caused hyperprogression of HNSCC 
supported the importance of B cells as anti-tumor immune cells. More specific targeting of B cell populations, such as regulatory $B$ cells, may be necessary to apply B cell depletion in cancer treatment.

HPD is a critical issue limiting the use of checkpoint inhibitors. Many studies revealed that some patients experience accelerated disease worsening after anti-PD-1 monotherapy $[27,28]$. Interestingly, chemotherapy combined with antiPD-1 agents carried a lower risk of HPD [27]. In the Keynote 048 trial, pembrolizumab monotherapy was associated with worse PFS than cetuximab/chemotherapy and pembrolizumab/chemotherapy in the first 6 months [29]. Our study also observed rapid progression in three patients treated using protocol 1 . In protocol 2, the patients received rituximab and chemotherapy simultaneously, and no one developed HPD, supporting the feasibility of rituximab and chemotherapy co-administration in patients with HNSCC.

Platinum agents are important cytotoxic treatments for HNSCC. Cisplatin is the backbone of induction chemotherapy and chemoradiotherapy [30,31], and patients with platinum resistance have poor outcomes. In prior research, immune checkpoint blockade prolonged the survival of patients who progressed on platinum treatment [32]. However, fewer than $20 \%$ of patients respond to immune checkpoint blockade. Cisplatin/gemcitabine produced a response rate of approximately $20 \%$ in R/M HNSCC. Meanwhile, the time to progression was only 4 months, and the duration was even shorter in patients who previously received chemotherapy [33]. The small sample size in our pilot study prevented us from analyzing treatment responses. However, although all six patients treated using protocol 2 had platinum-resistant tumors, two partial responses and one complete response were observed. Additionally, these three patients had disease-free intervals of 6-7 months. In the analysis of peripheral blood cells, these three responders had a higher ratio of cytotoxic $T$ cells to regulatory $T$ cells than non-responders. Several studies found that cytotoxic $T$ cells and regulatory $T$ cells can be used to stratify the immunophenotype of head and neck cancer and predict survival [34-36]. Whether differences in the TME cause diverse outcomes of B cell depletion warrants further investigation.

\section{Conclusions}

Treatment with rituximab alone can cause HPD in patients with HNSCC, whereas the co-administration of rituximab and cisplatin/gemcitabine appeared feasible and safe. Further studies are necessary to investigate the role of $B$ cells in the TME and develop new treatment strategies.

\section{Abbreviations}

CT computed tomography

EGFR epidermal growth factor receptor

HPD hyperprogressive disease

PD-1 $\quad$ programmed death 1

PFS progression-free survival

R/M HNSCC recurrent or metastatic head and neck squamous-cell carcinoma

TGKRs tumor growth kinetics ratios

TME tumor microenvironmen 


\section{Declarations}

\section{Ethics approval and consent to participate}

The study was conducted in accordance with the World Medical Association Declaration of Helsinki (version 2002) and approved by the China Medical University Hospital Review Board.

Patients provided IRB-approved, protocol-specific written informed consent prior to receiving study-specific treatment.

Availability of data and material

The datasets generated and analyzed in the current study are available from the corresponding author upon reasonable request.

\section{Competing interests}

The authors declare that they have no competing interests.

\section{Funding}

This work was supported by the National Health Research Institutes [NHRI-180A1- CACO-13191902]; and China Medical University [DMR-108-BC-6] and [DMR-110-019].

\section{Authors' contributions}

All authors contributed to the study conception and design. Material preparation, data collection and analysis were performed by $\mathrm{CYH}, \mathrm{MYL}, \mathrm{CYL}, \mathrm{CHH}$, WCC, CFC and CCL. The first draft of the manuscript was written by CCL and CYH and all authors commented on previous versions of the manuscript. All authors read and approved the final manuscript.

\section{Acknowledgements}

Not applicable

\section{References}

1. Argiris A, Karamouzis MV, Raben D, Ferris RL: Head and neck cancer. Lancet 2008, 371(9625):1695-1709.

2. Chow LQM: Head and Neck Cancer. N Engl J Med 2020, 382(1):60-72.

3. Burtness B, Harrington KJ, Greil R, Soulieres D, Tahara M, de Castro G, Jr., Psyrri A, Baste N, Neupane P, Bratland A et al: Pembrolizumab alone or with chemotherapy versus cetuximab with chemotherapy for recurrent or metastatic squamous cell carcinoma of the head and neck (KEYNOTE-048): a randomised, open-label, phase 3 study. Lancet (London, England) 2019, 394(10212):1915-1928.

4. Largeot A, Pagano G, Gonder S, Moussay E, Paggetti J: The B-side of Cancer Immunity: The Underrated Tune. Cells 2019, 8(5):449.

5. Affara NI, Ruffell B, Medler TR, Gunderson AJ, Johansson M, Bornstein S, Bergsland E, Steinhoff M, Li Y, Gong Q et al: B cells regulate macrophage phenotype and response to chemotherapy in squamous carcinomas. Cancer cell 2014, 25(6):809-821. 
6. Coiffier B, Lepage E, Briere J, Herbrecht R, Tilly H, Bouabdallah R, Morel P, Van Den Neste E, Salles G, Gaulard P et al: $\mathrm{CHOP}$ chemotherapy plus rituximab compared with $\mathrm{CHOP}$ alone in elderly patients with diffuse large-B-cell lymphoma. The New England journal of medicine 2002, 346(4):235-242.

7. Fischer K, Cramer P, Busch R, Stilgenbauer S, Bahlo J, Schweighofer CD, Bottcher S, Staib P, Kiehl M, Eckart MJ et al: Bendamustine combined with rituximab in patients with relapsed and/or refractory chronic lymphocytic leukemia: a multicenter phase II trial of the German Chronic Lymphocytic Leukemia Study Group. Journal of clinical oncology : official journal of the American Society of Clinical Oncology 2011, 29(26):3559-3566.

8. Winkler JK, Schiller M, Bender C, Enk AH, Hassel JC: Rituximab as a therapeutic option for patients with advanced melanoma. Cancer immunology, immunotherapy : C//2018, 67(6):917-924.

9. Barbera-Guillem E, Nelson MB, Barr B, Nyhus JK, May KF, Jr., Feng L, Sampsel JW: B lymphocyte pathology in human colorectal cancer. Experimental and clinical therapeutic effects of partial B cell depletion. Cancer immunology, immunotherapy : Cl/2000, 48(10):541-549.

10. Samlowski WE, Gundacker H, Kuebler JP, Giguere JK, Mills GM, Schuller DE, Ensley JF: Evaluation of gemcitabine in patients with recurrent or metastatic squamous cell carcinoma of the head and neck: a Southwest Oncology Group phase II study. Invest New Drugs 2001, 19(4):311-315.

11. Hertel LW, Boder GB, Kroin JS, Rinzel SM, Poore GA, Todd GC, Grindey GB: Evaluation of the antitumor activity of gemcitabine (2',2'-difluoro-2'-deoxycytidine). Cancer research 1990, 50(14):4417-4422.

12. Nowak AK, Robinson BW, Lake RA: Gemcitabine exerts a selective effect on the humoral immune response: implications for combination chemo-immunotherapy. Cancer research 2002, 62(8):2353-2358.

13. Saâda-Bouzid E, Defaucheux C, Karabajakian A, Coloma VP, Servois V, Paoletti X, Even C, Fayette J, Guigay J, Loirat $\mathrm{D}$ et al: Hyperprogression during anti-PD-1/PD-L1 therapy in patients with recurrent and/or metastatic head and neck squamous cell carcinoma. Ann Oncol 2017, 28(7):1605-1611.

14. Aklilu M, Stadler WM, Markiewicz M, Vogelzang NJ, Mahowald M, Johnson M, Gajewski TF: Depletion of normal B cells with rituximab as an adjunct to IL-2 therapy for renal cell carcinoma and melanoma. Annals of oncology : official journal of the European Society for Medical Oncology 2004, 15(7):1109-1114.

15. Gentles AJ, Newman AM, Liu CL, Bratman SV, Feng W, Kim D, Nair VS, Xu Y, Khuong A, Hoang CD et al: The prognostic landscape of genes and infiltrating immune cells across human cancers. Nat Med 2015, 21(8):938945.

16. Yuen GJ, Demissie E, Pillai S: B lymphocytes and cancer: a love-hate relationship. Trends in cancer 2016, 2(12):747-757.

17. Sharonov GV, Serebrovskaya EO, Yuzhakova DV, Britanova OV, Chudakov DM: B cells, plasma cells and antibody repertoires in the tumour microenvironment. Nature Reviews Immunology 2020:1-14.

18. Cabrita R, Lauss M, Sanna A, Donia M, Skaarup Larsen M, Mitra S, Johansson I, Phung B, Harbst K, VallonChristersson $\mathrm{J}$ et al: Tertiary lymphoid structures improve immunotherapy and survival in melanoma. Nature 2020, 577(7791):561-565.

19. Helmink BA, Reddy SM, Gao J, Zhang S, Basar R, Thakur R, Yizhak K, Sade-Feldman M, Blando J, Han G et al: B cells and tertiary lymphoid structures promote immunotherapy response. Nature 2020, 577(7791):549-555.

20. Petitprez F, de Reynies A, Keung EZ, Chen TW, Sun CM, Calderaro J, Jeng YM, Hsiao LP, Lacroix L, Bougouin A et al: B cells are associated with survival and immunotherapy response in sarcoma. Nature 2020, 577(7791):556560 .

21. Schioppa T, Moore R, Thompson RG, Rosser EC, Kulbe H, Nedospasov S, Mauri C, Coussens LM, Balkwill FR: B regulatory cells and the tumor-promoting actions of TNF-alpha during squamous carcinogenesis. Proceedings of 
the National Academy of Sciences of the United States of America 2011, 108(26):10662-10667.

22. Lindner S, Dahlke K, Sontheimer K, Hagn M, Kaltenmeier C, Barth TF, Beyer T, Reister F, Fabricius D, Lotfi R et al: Interleukin 21-induced granzyme B-expressing B cells infiltrate tumors and regulate $\mathrm{T}$ cells. Cancer research 2013, 73(8):2468-2479.

23. Andreu P, Johansson M, Affara NI, Pucci F, Tan T, Junankar S, Korets L, Lam J, Tawfik D, DeNardo DG et al: FcRgamma activation regulates inflammation-associated squamous carcinogenesis. Cancer cell 2010, 17(2):121-134.

24. Ammirante M, Luo JL, Grivennikov S, Nedospasov S, Karin M: B-cell-derived lymphotoxin promotes castrationresistant prostate cancer. Nature 2010, 464(7286):302-305.

25. Olkhanud PB, Damdinsuren B, Bodogai M, Gress RE, Sen R, Wejksza K, Malchinkhuu E, Wersto RP, Biragyn A: Tumor-evoked regulatory $\mathrm{B}$ cells promote breast cancer metastasis by converting resting CD4(+) T cells to Tregulatory cells. Cancer research 2011, 71(10):3505-3515.

26. Pylayeva-Gupta Y, Das S, Handler JS, Hajdu CH, Coffre M, Koralov SB, Bar-Sagi D: IL35-Producing B Cells Promote the Development of Pancreatic Neoplasia. Cancer discovery 2016, 6(3):247-255.

27. Ferrara R, Mezquita L, Texier M, Lahmar J, Audigier-Valette C, Tessonnier L, Mazieres J, Zalcman G, Brosseau S, Le Moulec S: Hyperprogressive disease in patients with advanced non-small cell lung cancer treated with PD1/PD-L1 inhibitors or with single-agent chemotherapy. JAMA oncology 2018, 4(11):1543-1552.

28. Saâda-Bouzid E, Defaucheux C, Karabajakian A, Coloma VP, Servois V, Paoletti X, Even C, Fayette J, Guigay J, Loirat D: Hyperprogression during anti-PD-1/PD-L1 therapy in patients with recurrent and/or metastatic head and neck squamous cell carcinoma. Annals of Oncology 2017, 28(7):1605-1611.

29. Burtness B, Harrington KJ, Greil R, Soulières D, Tahara M, de Castro G, Jr., Psyrri A, Basté N, Neupane P, Bratland $\AA$ et al: Pembrolizumab alone or with chemotherapy versus cetuximab with chemotherapy for recurrent or metastatic squamous cell carcinoma of the head and neck (KEYNOTE-048): a randomised, open-label, phase 3 study. Lancet 2019, 394(10212):1915-1928.

30. Vermorken JB, Remenar E, van Herpen C, Gorlia T, Mesia R, Degardin M, Stewart JS, Jelic S, Betka J, Preiss JH et al: Cisplatin, fluorouracil, and docetaxel in unresectable head and neck cancer. The New England journal of medicine 2007, 357(17):1695-1704.

31. Bernier J, Domenge C, Ozsahin M, Matuszewska K, Lefebvre JL, Greiner RH, Giralt J, Maingon P, Rolland F, Bolla $\mathrm{M}$ et al: Postoperative irradiation with or without concomitant chemotherapy for locally advanced head and neck cancer. The New England journal of medicine 2004, 350(19):1945-1952.

32. Bauml J, Seiwert TY, Pfister DG, Worden F, Liu SV, Gilbert J, Saba NF, Weiss J, Wirth L, Sukari A et al: Pembrolizumab for Platinum- and Cetuximab-Refractory Head and Neck Cancer: Results From a Single-Arm, Phase II Study. Journal of clinical oncology : official journal of the American Society of Clinical Oncology 2017, 35(14):1542-1549.

33. Yang MH, Chang PM, Tzeng CH, Chang SY, Chu PY, Tai SK, Tsai TL, Wang YF, Huang JL, Wang HM et al: Promising overall survival of patients with recurrent/metastatic squamous cell carcinoma of head and neck receiving gemcitabine plus cisplatin treatment: report of a multi-center phase II study. Cancer Chemother Pharmacol 2010, 65(2):259-265.

34. Distel LV, Fickenscher R, Dietel K, Hung A, Iro H, Zenk J, Nkenke E, Büttner M, Niedobitek G, Grabenbauer GG: Tumour infiltrating lymphocytes in squamous cell carcinoma of the oro- and hypopharynx: prognostic impact may depend on type of treatment and stage of disease. Oral Onco/2009, 45(10):e167-174. 
35. Wallis SP, Stafford ND, Greenman J: Clinical relevance of immune parameters in the tumor microenvironment of head and neck cancers. Head Neck 2015, 37(3):449-459.

36. Echarti A, Hecht M, Büttner-Herold M, Haderlein M, Hartmann A, Fietkau R, Distel L: CD8+ and Regulatory T cells Differentiate Tumor Immune Phenotypes and Predict Survival in Locally Advanced Head and Neck Cancer. Cancers (Basel) 2019, 11(9):1398.

\section{Figures}

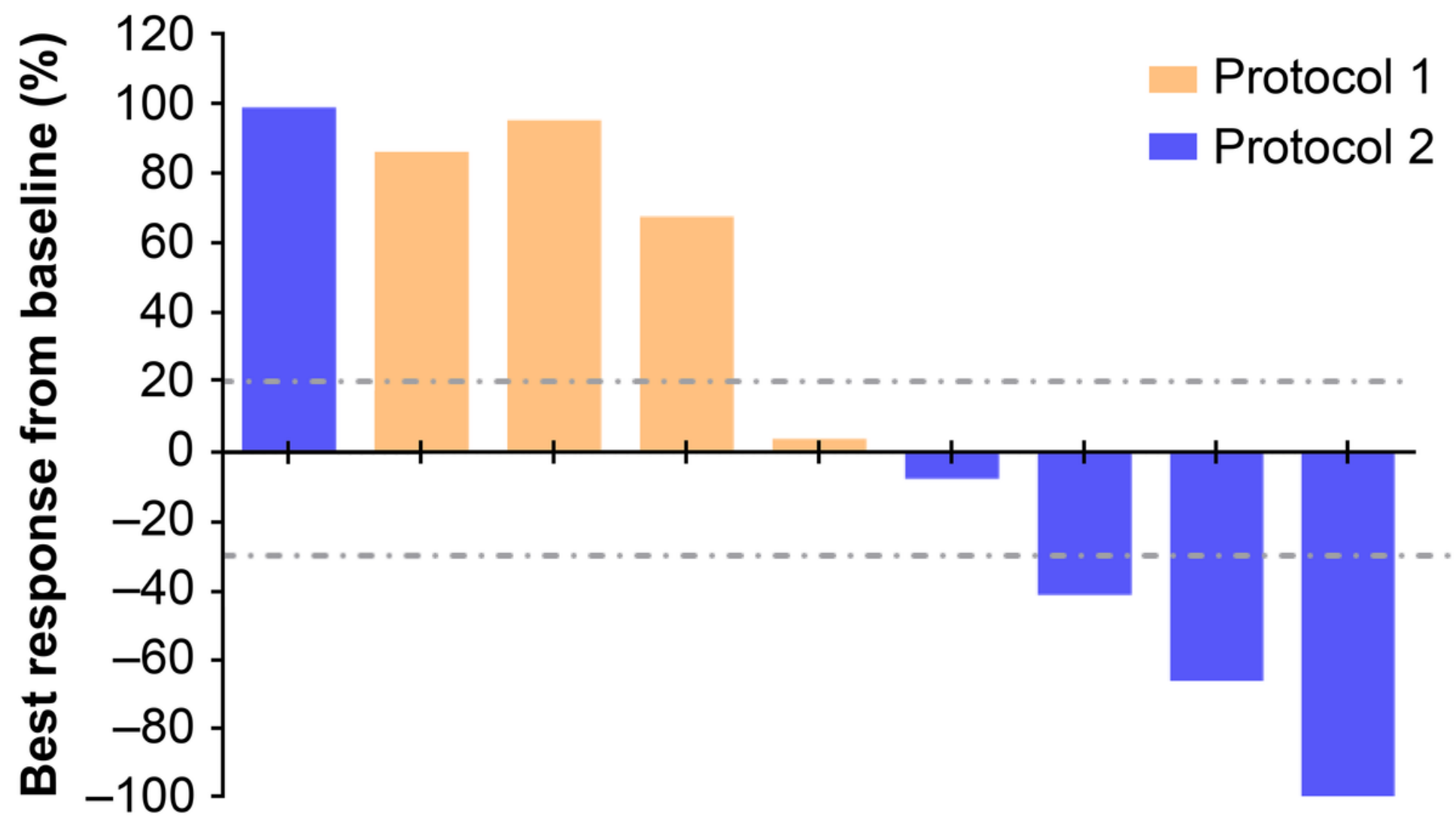

Figure 1

Waterfall plot of the best clinical response (RECIST 1.1) after treatment. 


\section{Baseline}
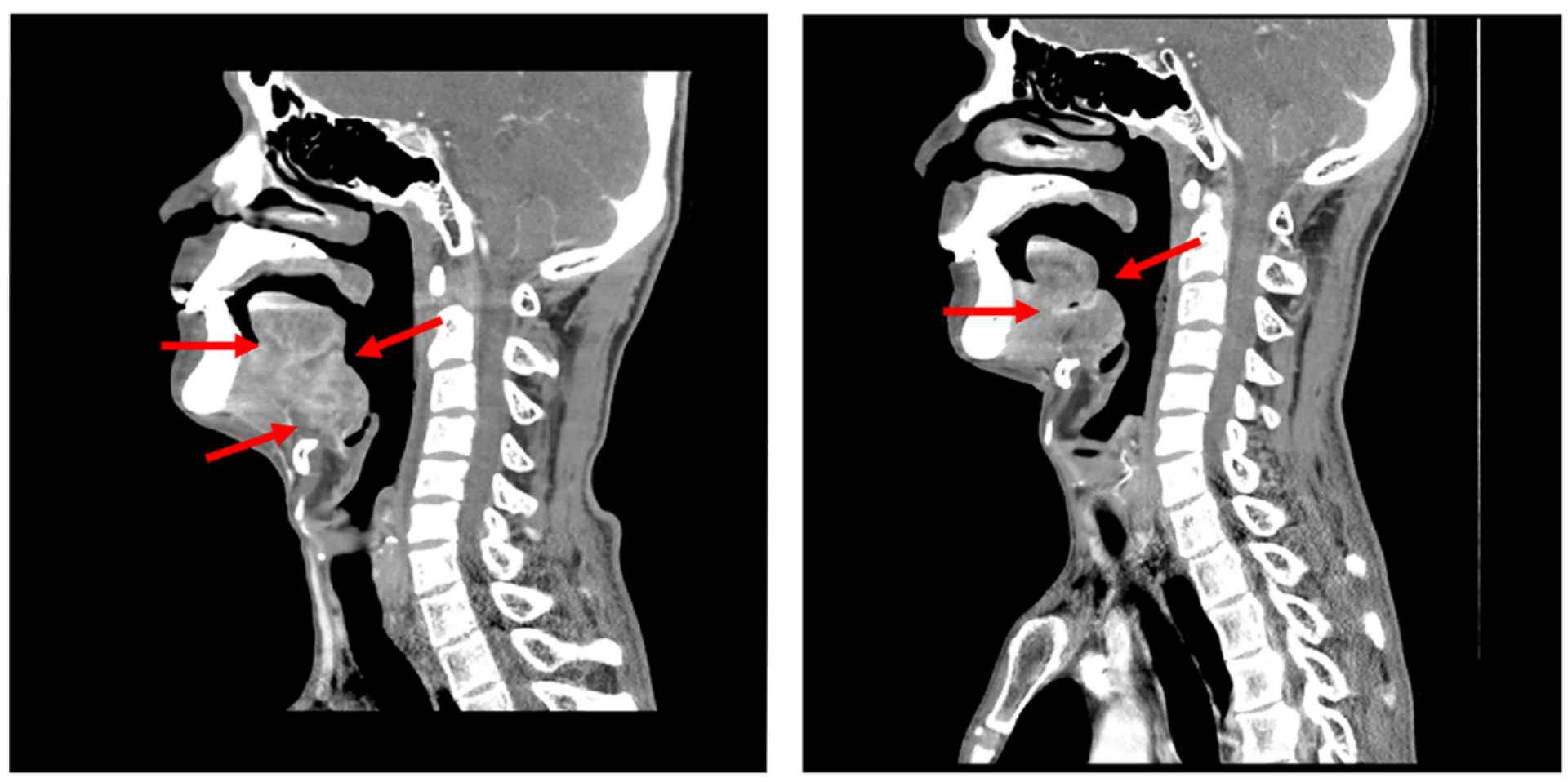

Figure 2

Computed tomography (CT) images of one responder. The patient had primary tongue cancer that was refractory to chemoradiotherapy using triweekly cisplatin $100 \mathrm{mg} / \mathrm{m} 2$. (a) Baseline CT. (b) After 2 months, CT revealed a partial response. 


\section{Variation of tumor burden $(\mathrm{mm})$}

- Patient 2 TGKR $=3.705$

- Patient 3 TGKR $=2.056$

$\neg$ Patient 4 TGKR $=3.3$

$\rightarrow$ Patient 7 TGKR $=1.022$

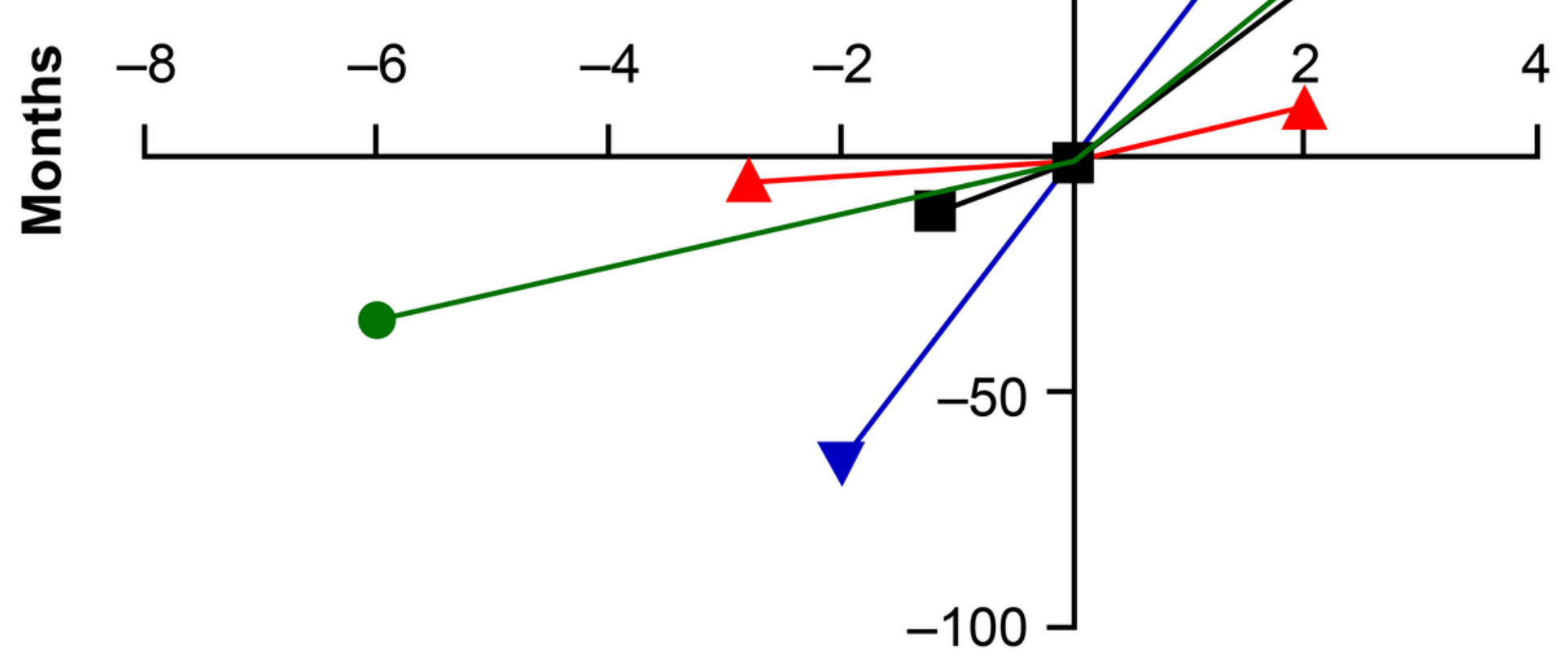

\section{TGKR}

\section{Figure 3}

The tumor size before treatment, at baseline, and after treatment in patients with progression. The tumor growth kinetics ratio (TGKR) is also presented. 
a

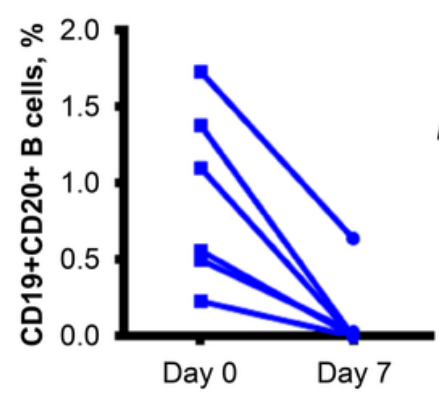

d

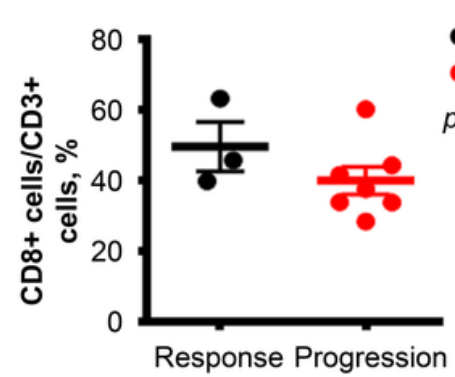

g

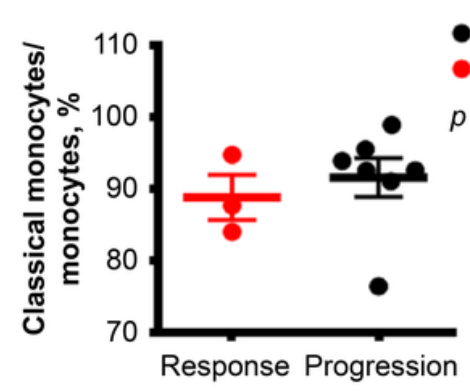

b

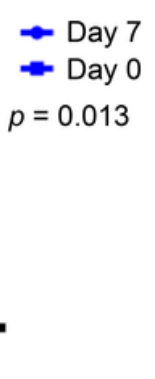

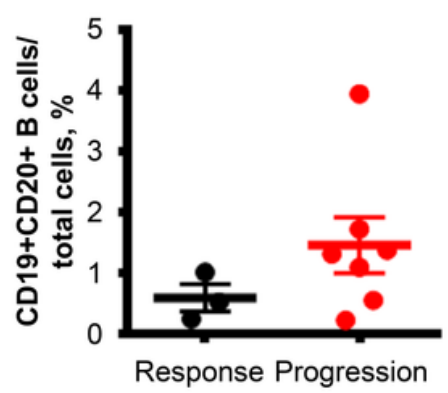

e

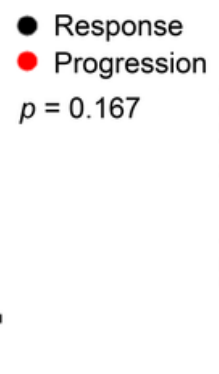

- Response

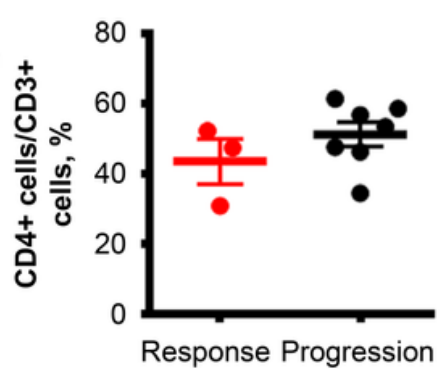

f
- Progression

- Response

$p=0.233$
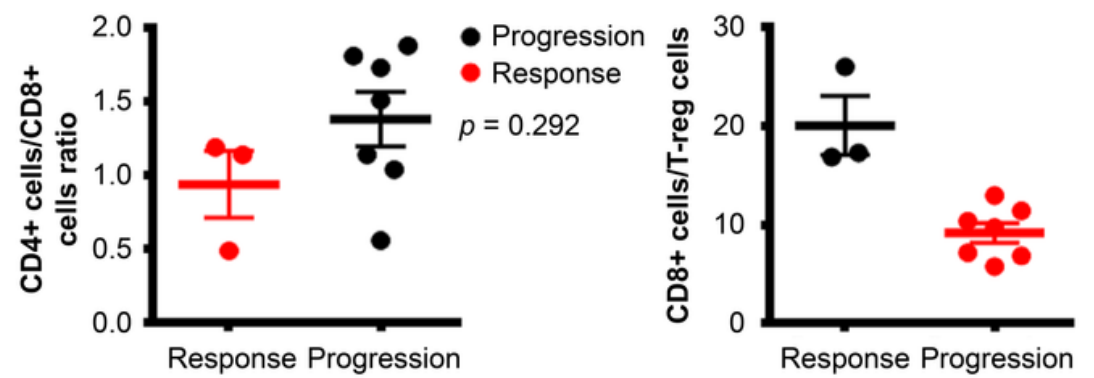

- Response

- Progression $p=0.017$

- Progression $p=0.183$

h

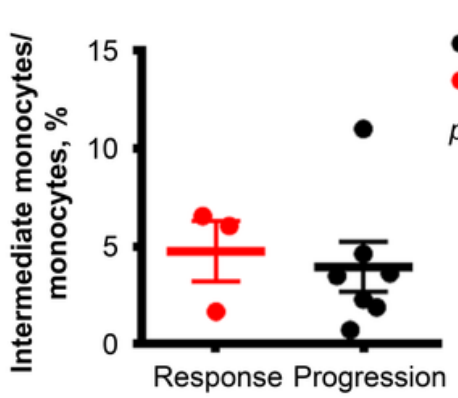

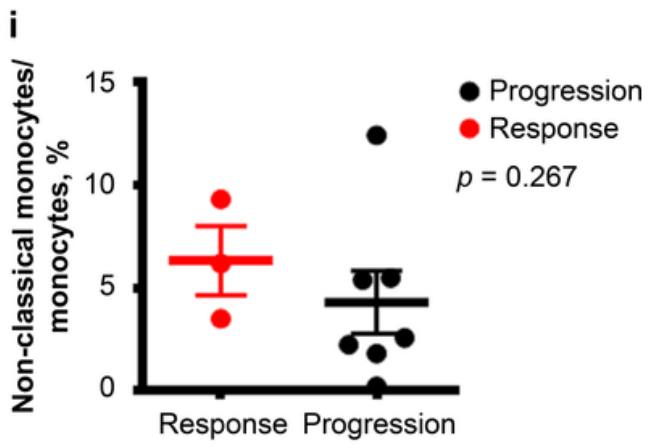

Figure 4

Peripheral blood immune cell profile. CD20 count on days 0 and 7. (a) Peripheral immune cell profile in non-classical monocyte responders and non-responders including (b) CD19+CD20+, (c) CD4, (d) CD8, (e) CD4/CD8 ratio, (f) regulatory $\mathrm{T}$ cell/CD8 ratio, $(\mathrm{g})$ classical monocytes, $(\mathrm{h})$ intermediate monocytes, and (i) non-classical monocytes. The results were analyzed using the Mann-Whitney $U$ test $(n=3+7)$. 